\title{
A hiperatividade no tempo de Minkowski
}

Paulo Germano Marmorato ${ }^{1}$

\section{Resumo}

Os fenômenos da atividade acompanham o homem de modo essencial, desde como condição para manutenção de sua vida até suas realizações mais particulares e sublimes. O diagnóstico de transtorno de déficit de atenção e hiperatividade coloca a questão de uma psicopatologia baseada em um aspecto geral da atividade humana, a atividade. No entanto, ao contrário de outros diagnósticos psiquiátricos, a hiperatividade não teve seus aspectos psicopatológicos investigados através do método fenomenológico. Baseando-se na obra Le Temps Vécu, de Eugène Minkowski, o presente artigo visa mostrar como aspectos próprios da temporalidade vivida na hiperatividade podem oferecer meios preciosos para a compreensão de sua psicopatologia.

Palavras-chave: Psicopatologia; Atividade; Hiperatividade; Eugène Minkowski.

\section{Hiperactivity in Minkowski's time}

\begin{abstract}
Activity's phenomena characterize the human being in its essence, from the basic conditions to life maintenance up to human's most particular and sublime accomplishments. The attention deficit hyperactivity disorder diagnosis puts in evidence a psycopathology based in one general aspect of human activity. However, the psycopathology of hyperactivity was not much studied through phenomenological method as other psychiatric diagnosis. Based in Eugène Minkowski's book Le temps vécu, this article tries to show how lived temporality in hyperactivity can offer precious ways to its psycopathology understanding.
\end{abstract}

Key-words: Psycopathology; Activity; Hyperactivity; Eugène Minkowski.

\footnotetext{
${ }^{1}$ Psiquiatra da infância e adolescência. Coordenador do Ambulatório de Socialização do SEPIA IPq HCFMUSP. Email: pgmarmorato@yahoo.com.br
} 


\section{Introdução}

O ser humano é profundamente marcado pelas suas ações, por aquilo que faz, pelas suas atitudes. A atividade é uma condição essencial do homem e da vida. Se formos mais longe ainda, mesmo a matéria sem vida, por mais estática que pareça, é constituída de partículas em movimento, um princípio, até onde se sabe, universal. O princípio heraclitiano, de que tudo é movimento, tudo flui como um rio, rege inconteste há mais de dois mil anos. Assim, o homem carrega no seu fundamento corpóreo movimentos, incontáveis e incessantes atividades de sistemas, órgãos, células e organelas, que mantém o equilíbrio instável mantenedor de sua vida. E se dermos um salto dimensional e considerarmos o homem consciente, veremos que os anseios e objetivos humanos constituem-se de atividades: o trabalho, o estudo, a religião, o lazer, o contato social. A atividade é a uma só vez condição que o ser humano compartilha com o universal, assim como, num outro extremo, a forma de expressão de suas particularidades, do modo único de cada indivíduo ser. Como habitualmente ocorre com o que é essencial, o tema da atividade, de tão evidente, passa ao largo de nossa reflexão cotidiana. Assim também podemos dizer do que se refere à psicopatologia e à psiquiatria, em que, no mais das vezes, formas as mais diversas de atividades indicativas de alterações mentais são inevitavelmente abordadas, mas a atividade como tal é pouco observada. Nas últimas décadas, um termo relativamente novo, hiperatividade, tem ganhado crescente destaque no mundo da psiquiatria e em outros setores da sociedade. A inclusão dos diagnósticos de "reação hipercinética" na segunda edição do DSM em 1968 e de "síndrome hipercinética" na CID-9, em 1977, foi o primeiro passo para a maior divulgação do "transtorno de déficit de atenção e hiperatividade" (TDAH) a partir da publicação do DSM-III, em 1980 (APA, 1994). De modo particular, este diagnóstico colocou o tema da atividade em seu aspecto geral como centro de um processo patológico do comportamento humano. Desde então houve um aumento imenso na quantidade de estudos dedicados ao TDAH, assim como no número de indivíduos assim diagnosticados, na sua grande maioria crianças e adolescentes. À medida que veio sendo mais reconhecido, esse diagnóstico passou a encontrar crescentes oposições e questionamentos acerca de sua validade. Entre muitos argumentos para o ceticismo, alega-se que não há marcadores neurobiológicos consistentes que se apliquem a todos indivíduos diagnosticados. O uso de psicofármacos estimuladores do sistema nervoso central em crianças e adolescentes também é um dos aspectos que motiva críticas as mais ferrenhas. Desse modo, boa parte do debate a respeito fica centrado na busca de 
dados científicos que justifiquem ou expliquem o diagnóstico e na pertinência ou não das modalidades de tratamentos realizados.

Esse artigo tem objetivo de iniciar um estudo orientado pela psicopatologia fenomenológica a respeito da hiperatividade. Sob esse ponto de vista, convém deixarmos de lado as ideias previamente estabelecidas a seu respeito. O próprio julgamento a respeito da validade de sua existência como diagnóstico não cabe neste momento, seria precipitado, sujeito a preconceitos das mais naturezas. Assim, muito antes de considerarmos o diagnóstico em si, um construto nosológico mais complexo na hierarquia psicopatológica, cabe a tarefa de nos direcionarmos mais atentamente aos fenômenos nos quais se baseia.

Os manuais diagnósticos atuais valem-se de critérios como "frequentemente agita as mão ou os pés ou se agita na cadeira" ou "com frequência tem dificuldade para brincar ou se envolver silenciosamente em atividades de lazer". Tais construtos assumem como simples, clara e compartilhável a caracterização desses comportamentos, usando praticamente o senso comum, ou uma atitude natural para discerni-la. Daí a facilidade de aplicação, sua funcionalidade e a expansão de seu uso. Cabe questionar, no entanto, se essa simplicidade de uso não é responsável pela ampla margem de enganos e precipitações que se verifica na clínica e que permite uma grande quantidade de críticas, inclusive o questionamento a respeito de sua real existência. Nossa postura aqui, no entanto, não é a de jogar o bebê fora com a água do banho. Não é por haver problemas ou fragilidades no diagnóstico que o fenômeno de algo que poderíamos chamar de hiperatividade humana simplesmente não existe. Vale inclusive lembrar que se considerarmos a milenar história dos conceitos psicopatológicos como mania ou melancolia, a hiperatividade é praticamente neonata e seria até injusto cobrar maior clareza a um bebê psicopatológico. Assim como esses anciões conceitos, a hiperatividade irá requerer a decantação que apenas o tempo proporciona para ganhar consistência e credibilidade.

Dentro da ideia husserliana que exorta o direcionamento "às coisas mesmas" quando da busca dos fenômenos, cabem questões simples como: o é que atividade? Como se manifesta? Como é vivido o mundo a partir da experiência de um indivíduo dito hiperativo? É fato que o crescente interesse pelo TDAH ocorreu em uma época em que a psicopatologia (no sentido forte do termo) passava por uma lenta e contínua perda de prestígio por parte da psiquiatria oficial, que passou a valorizar modos objetivos e quantificáveis, visando a aproximar-se das ciências duras. Nesse sentido, parece-nos que a hiperatividade carece da investigação psicopatológica que foi significativamente realizada nos quadros clássicos de 
psicoses, mania, melancolia entre outros e apresenta uma lacuna em sua apreensão. Assim, estes últimos têm seus diagnósticos reduzidos a fórmulas tão simplistas quanto o TDAH, mas estudos psicopatológicos clássicos lhe conferem uma consistência que se aproxima mais da complexidade que o psiquismo humano possui. Em outras palavras, o ponto de vista fenomenológico pode fornecer visões relevantes para compreensão dos quadros e dos sujeitos que os apresentam. Essa maior proximidade com o fenômeno mórbido em si assegura uma credibilidade aos diagnósticos, tornando-se uma alternativa ao simplismo do DSM e da CID.

\section{"A atividade e a espera" de Minkowski}

Dentre as mais originais contribuições à psicopatologia fenomenológica, merece destaque o livro Le temps vécu, ( $\mathrm{O}$ tempo vivido, não editado em língua portuguesa), de Eugene Minkowski, publicado em 1933. Esta obra é constituída de dois livros, o primeiro um "Ensaio sobre o aspecto temporal da vida", o segundo, dedicado à "Estrutura espaço-temporal dos distúrbios mentais". No primeiro livro, após fazer considerações sobre o tempo-qualidade e caracterizar seu conceito de élan pessoal e contato vital com a realidade, Minkowski dedica-se à ideia de futuro e suas relações com a temporalidade humana. Neste capítulo, são feitas importantes considerações sobre a "a atividade e a espera". Apresentaremos aqui uma tradução livre de seus principais trechos, os quais tomaremos como base para o desenvolvimento de nossas ideias ulteriores a respeito da hiperatividade. Ao leitor sugerimos naturalmente a leitura do próprio Le temps vécu para uma apreensão dessa obra em seu contexto maior.

“A atividade é uma manifestação global do ser vivo, não pode ser decomposta em uma multiplicidade de ações diferentes, cada qual dirigida a uma meta precisa. É um fenômeno essencial da vida. Tudo o que vive é ativo e tudo o que é ativo vive.

A atividade é um fenômeno de natureza temporal; não faz parte do ser, mas do devir. Ela comporta o fator de futuro; pela sua atividade o ser vivo se dirige adiante, ele tende ao futuro, cria-o diante de si. Comporta também o fator de duração; a atividade é, no fundo, a duração vivida ligada à idéia de ser vivo; ela é 
uma duração ativa, ou melhor, uma duração orientada ao futuro. Inversamente, toda duração vivida que tende ao futuro só pode ser atividade.

Preferimos não falar de "sentimento" a propósito da atividade. Este é um fenômeno que nos é por demais próximo, que é demasiado "à mão" para que possamos senti-lo na realidade, tampouco, aliás, para que possamos representá-lo a nós; sempre aí, é bem mais um dado imediato de nossa consciência.

Tomada em uma de suas subdivisões, a atividade prossegue naturalmente mais longe. A atividade não se deixa fixar nem parar. Assim, ela sempre entra em contato com um futuro imediato. De forma elementar, é a atividade que nos dá a noção desse futuro imediato. É como o olhar a percorrer uma extensão, o que não que dizer que possa alcançá-la em sua totalidade. Mas a atividade não é um simples olhar; ela se encontra no plano do eu que tende a alguma coisa. Assim, ela é um verdadeiro "caminhar" adiante e constitui o único modo de realmente avançar na vida.

A atividade funciona como fundo natural para o fenômeno da obra de afirmação do eu. É somente pela minha atividade que consigo criar alguma coisa, ainda que a criação não seja ligada de modo imediato à atividade. Por outro lado, é somente a obra que parece poder se destacar da atividade, sem ser inteiramente por ela absorvida.

No entanto, as características temporais que acabamos de por em relevo não esgotam o fenômeno da atividade. Além do futuro, há ainda como que uma outra direção na atividade. Há expansão nela. $\mathrm{O}$ ser vivo se desenvolve na sua atividade e gostariamos dizer que ele se torna "maior". Mas, na verdade, essa expansão não consiste em um aumento de volume. Mesmo havendo na atividade a clara sensação de expansão, não me sinto de nenhuma forma ultrapassar os limites, no sentido físico da palavra, que possuia anteriormente. Isso não impede que haja como que um "maior" na atividade; no entanto esse maior não é o resultado de uma comparação entre duas grandezas estáticas, mas visa unicamente ao tornar-se maior, no que este possui de dinâmico em si, sem que, em algum momento que seja, possa ser o caso de um ser maior propriamente dito. Na atividade, sentimonos desenvolver, permanecendo, no fundo, os mesmos.

Vemos desenhar-se como que uma esfera de nossa atividade diante de nós, esfera que, determinada pela nossa atividade, não tem nada de esfera no sentido geométrico do termo, que, não obstante, possui alguma coisa de comum com o espaço. Mas não espaço geométrico, e sim, um espaço vivido. Na forma em que 
vivemos o futuro, tempo e espaço parecem intimamente ligados um ao outro. Eles se reencontram ou até mesmo se confundem no seu caráter irracional.

É a própria atividade que determina sua esfera. Os limites desta esfera não vêm determinados por forças externas, mas são dados pela própria atividade. É o que faz com que, longe de me sentir aprisionado pela esfera da minha atividade e de me chocar contra suas paredes, sinto-me, ao contrário, à vontade, e sinto prazer em me mover sem entraves.

A atividade contém em si um fator de limitação. É uma limitação dinâmica, pois é determinada pela própria atividade. É mais uma limitação qualitativa; pois não se trata de casos em um meio homogêneo, nem mesmo de centros de atividade em uma atividade universal, mas disso que por sua atividade o ser vivo se separa de alguma coisa que é qualitativamente muito diferente dele, a saber, de um meio inerte e não-individual no qual sua atividade se abre e se desenvolve livremente. A atividade enquanto devir traz consigo a noção de um meio que, este, não é mais devir.

O eu só se separa do meio ambiente pela sua atividade, é ela que traz, por excelência e primitivamente, a noção de limitação do eu.

É apenas progressivamente que aprendo a medir meu esforço, a conhecer a existência dos obstáculos e a conseguir, apesar deles, o que quero; a atividade, ao contrário, constitui o quadro geral e indispensável no qual acumularei essas experiências. A limitação na qual falamos é bem mais uma limitação pela atividade que uma limitação da atividade. Ela não tem nada a ver com um sentimento de impotência. Assim, a atividade não comporta em si mesma um sentimento de potência nem um sentimento de fraqueza; ela é um fenômeno primitivo e quase neutro. Digo quase porque, no fundo, existe algo de positivo nela. Em alguns momentos da vida nos deixamos simplesmente viver; a atividade elementar parece então bastar-se a si mesma; ela se aproxima aqui de fenômenos de sintonia e de repouso, diferenciando-se bem pelas suas próprias características. Ela é acompanhada nesses momentos de uma tintura particular, suficientemente discreta, de fato, mas suficientemente clara para ser percebida; essa tintura, creio que poderíamos chamá-la assim: a alegria elementar de viver.

O fenômeno vital que se opõe à atividade, situando-se no mesmo plano que ela é a espera. $\mathrm{Na}$ atividade tendemos em direção ao futuro, na espera, ao contrário, vivemos o tempo em sentido inverso, por assim dizer; vemos o futuro vir em direção a nós e esperamos que esse futuro (previsto) torne-se presente. 
A espera, enquanto atitude vital é bem mais elementar, ela se apresenta em sua estrutura primeira de outra forma. Ela engloba todo o ser vivo, suspende sua atividade e o fixa, angustiado, na espera. Ela contém um fator de parada brutal em si e deixa o indivíduo ofegante. A espera primitiva é assim sempre ligada a uma angústia intensa; ela é sempre angustiante. Isso não tem nada de surpreendente, já que ela é uma suspensão da atividade que, por sua vez, é a própria vida. Ocasionalmente, sem nenhuma razão aparente, a imagem da morte surge em nós, a morte suspensa, em toda sua potência destrutiva, sobre nós e aproximando-se em grandes passos; a angústia, o terror nos oprime; impotentes, esperamos a bem próxima aniquilação fatal a que somos condenados sem misericórdia. Na presença de um perigo iminente, esperamos, fixados no lugar, como que paralisados pelo terror. Estes são as ilustrações, entre as melhores, da espera.

A espera é um fenômeno de ordem temporal. Contém o futuro em si e esse é um futuro imediato. Nesse ponto de vista a espera se encontra no mesmo plano que a atividade.

$\mathrm{Na}$ atividade eu tendo ao futuro, na espera eu vivo o tempo numa direção oposta. Aqui, sinto o futuro vir, de uma forma imediata, com toda sua impetuosidade, em direção a mim. Além disso, a atividade contém a duração em si, ela é duração ativa. Não é o mesmo com a espera. Por sua natureza, esta é apenas um instante, uma suspensão instantânea da vida e é somente dessa forma que ela consegue integrar-se à vida que é atividade por excelência. Na espera, por paradoxal que possa parecer, vivo a instantaneidade. A espera aproxima-se assim bem mais da sucessão, tal com a descrevemos, do que da duração vivida. Na espera não há duração, não há organização no tempo, mas há como que dois elementos do tempo que se sucedem, que se sucedem aliás de modo particular, o momento a chegar sendo vivido quase sozinho, na sua marcha impetuosa em direção a mim, a exclusão do momento presente. Toda ênfase cai no momento da sucessão, este momento a absorver, por assim dizer, todo o futuro e deixando subsistir o momento, que o precede apenas na forma de uma simples desconfiança. Seria também falso dizer que na espera eu vivo o presente e o futuro imediato, religados um ao outro: na realidade vivo apenas o futuro que, como tal, tende a tornar-se presente. A espera possui então isto em comum com a sucessão, no sentido de que ela repousa sob um limite vivido entre dois eventos, mas difere no que o momento a vir domina inteiramente a situação e que "ser dois" encontra-se nesse fato, como que deformado. 
Além dessa diferença de ordem temporal, constatamos uma diferença de outra ordem. Na espera, há um encolhimento do ser vivo, um "tornar-se menor" que vem se opor à expansão da atividade. Na espera, o ser dobra-se sobre si mesmo, dir-se-ia que procura expor o mínimo de si aos choques do ambiente hostil e, assim fazendo, ele separa-se desse ambiente, retira seus próprios limites em relação a ele.

Se na direção centrífuga o ser vivo separa-se do ambiente pela sua atividade, na direção centrípeta ele puxa seus limites pela espera. É provavelmente a elas duas que a atividade e a espera determinam a atitude geral do indivíduo no mundo. Se na atividade, vindo se desdobrar no meio vazio, sou quase um todo, na espera, reduzido a minha mais simples expressão, por assim dizer, sob a ameaça de ser engolido pelo devir ambiente, sou quase um nada, é provavelmente graças à ação conjugada da atividade e da espera que sou o que sou, isto é, um ser limitado, vivendo no mundo, susceptivel de desdobrar sua atividade, susceptível também de suportar os choques vindos de fora. É provavel igualmente que a passagem da atenção à atividade e vice-versa contribuam em fazer nascer em nós noção de uma superfície ativo-sensitiva, sede da interação do eu e do meio ambiente imediato. Aqui tempo e espaço se confundem numa espécie de solidariedade vivida, solidariedade na qual o espaço se encontra assimilado ao tempo e não inversamente.

A atividade nos coloca em contexto, nos situa no mundo, nos confere apreensão corporal e mental, coloca nossa vida em perspectiva, em movimento". (Minkowski, 1933/1995, p. 83-91)

\section{Psicopatologia}

Ao seguirmos as ideias de Minkowski a respeito da atividade e da espera, como uma hiperatividade poderia se configurar? Da atividade certamente pode-se derivar diversas dimensões e subdivisões. Se considerarmos a atividade no modo sugerido por Minkowski, como manifestação global, como um conjunto ações na sua totalidade em um indivíduo, independentemente de características particulares, é possível conceber um modo global em que suas atividades sejam excessivas. Mas isto pouco nos esclarece, já que os critérios desse excesso devem estar certamente estabelecidos em comparação, de acordo com determinado parâmetro, quase sempre com fortes determinantes sociais. Vale lembrar que o 
termo alternativo à hiperatividade, a hipercinesia, pela sua maior simplicidade, permite uma maior clareza de designação, já que se refere a uma grande ou excessiva movimentação, sem o caráter mais elaborado sugerido por atividade. De qualquer forma, nos limitaremos neste texto à hiperatividade de manifestação global, aquela que se identifica com o padrão habitual de uma pessoa, em que esta se reconheça e se identifique. Nesses casos a hiperatividade faz parte do modo natural de ser do indivíduo, que no mais das vezes não se incomoda ou sofre com essa condição. Assim, não são serão discutidas formas em que a hiperatividade se manifesta circunstancialmente, como em quadros como a mania, estados de excitação catatônica ou crises ansiosas.

Na atividade, como postulado por Minkowski, o campo de consciência dirige-se a um futuro imediato. Um aumento de velocidade gerado pela hiperatividade requer a manutenção de foco da consciência em um ponto em constante mudança para os ajustes necessários para a continuidade da ação. Em alta velocidade, quanto mais automatizados estes ajustes, mais eficientes os movimentos. Os dados do entorno necessariamente passarão mais rapidamente, na periferia do campo de visão, o que não permite uma apreensão mais refinada deles. Caso isto ocorra, o risco de acidente é grande e a velocidade desejada será abortada na raiz. A frequente predileção de crianças e jovens hiperativos por esportes atesta esse estar em ressonância com um tempo acelerado. De modo interessante, vale observar como os vídeo-games vieram a conferir a imersão em um mundo veloz sem a necessidade da hipercinesia física, mas abarcando a mente e, mais importante, através da participação ativa e protagonista. Disposições dessa natureza não possuem necessariamente um caráter anormal ou patológico. $\mathrm{Na}$ verdade, são desejáveis em diversas situações - inclusive as de sobrevivência em reações de luta ou fuga - e mesmo valorizados em diversos contextos sociais. $\mathrm{Na}$ constituição hiperativa, no entanto, essa tendência predominaria também em contextos vitais em que uma velocidade mais baixa e um modo de consciência diferente são requisitados. A apreensão do mundo de modo contemplativo, a atenção aos detalhes, a observação de nuances fica bastante diminuída ocasionando redução de repertório vivencial. A intensidade de estímulos e sua movimentação torna-se necessária para evitar a queda no tédio.

A hiperatividade acarretaria uma disposição de consciência menos flexível para modulações de velocidade e apreensão da realidade diferentes. Isso incorre em predomínio de vivências - marcadas pela novidade e pelas sensações - que são mais importantes para ações no aqui e agora. Em contrapartida, as experiências marcadas pelo já vivido e pelo pensamento - mais importantes para construções a longo prazo estariam enfraquecidas. Justamente porque a experiência requer um 
tempo em que o futuro imediato não está em jogo, um tempo voltado à reflexão sobre o passado, sobre os frutos das atividades.

A natural expansão do eu gerada pela atividade remete ao desenvolvimento, ao crescimento, à vida. As potências individuais têm aí sua forma de expressão e as possibilidades da existência se configuram no real. $\mathrm{Na}$ hiperatividade, no entanto, essa expansão, que deixa a impressão de energia e vivacidade, tende a gerar uma expansão excessiva que, no seu movimento centrífugo quase contínuo, ocasiona como que um efeito de bolha: expansão excessiva pois, inflada, gera contornos frágeis, de pouco conteúdo que a sustente. $\mathrm{Na}$ hiperatividade, as atividades tendem a trazer pouco resultado, deixam pouca obra finalizada, são atividades empobrecidas, pois pouco duram além do momento de sua realização.

A dialética relação de expansão e contração, de direcionamento centrífugo e centrípeto, de atuação no meio e de recepção do meio estaria desequilibrada na hiperatividade, com claro predomínio da expansão, do direcionamento centrífugo, da atuação no meio. Os resultados da síntese desequilibrada dificultariam a formação de dois fatores importantes para uma expansão forte e duradoura: a construção de experiência e a realização de obras.

A atividade, como dito por Minkowski, delimita seus próprios limites, de dentro para fora. Devemos considerar se, no entanto, a condição hiperativa não proporciona ao seu agente um frequente choque de suas ações expansíveis com objetos os mais diversos, inicialmente o chão e paredes, passando por pessoas até regras e convenções sociais. Estes choques, forçosamente trazendo um "não" ao agente, impõem-lhe a espera, um futuro que vem de fora. Nesses casos, os constantes choques poderiam impor-se como forçosa experiência.

Parece ser bastante consistente a observação de que uma parcela expressiva de indivíduos hiperativos apresenta comportamentos agressivos e mesmo antissociais. Devemos no questionar se a mencionada experiência de choques não tem um papel importante no sentido de direcionar um hiperativo à busca de habilidades para o choque, o confronto violento que sua experiência mostra ser necessária.

Possivelmente por configurar-se como um modo de ser apropriado a diversas situações e demanda humanas, a constituição hiperativa não tenha senão recentemente sido reconhecida como um quadro patológico. Em relação a essa perspectiva histórica, o argumento de que a hiperatividade seria fruto de crianças expostas ao mundo contemporâneo e não uma condição pessoal parece-nos 
equivocado. De várias maneiras, um mundo de fato acelerado poderia ser mais facilmente sintonizável por crianças hiperativas. Nesse sentido, o motivo maior de desadaptação de crianças hiperativas não seria a influência da aceleração e a crescente demanda por rendimento, por diversidade de habilidades, por múltiplas realizações. Dentro da ordem atual, indivíduos hiperativos não seriam necessariamente um problema, desde que efetivos, desde que suas atividades fossem produtivas, gerassem rendimento. Na hiperatividade a que nos referimos as atividades trazem pouco resultado, deixam pouca obra, são atividades empobrecidas, pois pouco duram além do momento de sua realização.

De fato, hiperativos ficariam em desvantagem pela dificuldade em transitar no mundo em outras velocidades. A compreensão do mundo não lhes está alterada, não lhe causa estranhamento, mas haveria nesses casos um descompasso de tempos, causando mais choques, atropelos, desencontros e conflitos. Nesse sentido a aquisição da valorizada habilidade no mundo grego clássico, o kairos, a habilidade da adequada ação no momento oportuno, lhes estaria mais distante, dificultando a realização de atividades pertinentes e duráveis.

Por fim, vale mencionar que as reflexões expostas neste artigo têm um caráter preliminar e especulativo nesse terreno pouco explorado da psicopatologia da atividade. Colocar em pauta algumas das ideias de Minkowski e mostrar sua potencial fecundidade para a psicopatologia contemporânea cumpre nosso maior escopo. Voltando à tradição da psicopatologia fenomenológica, as ideias aqui desenvolvidas mostrarão alguma validade apenas se observadas na base fundamental para nosso conhecimento, os estudos de casos clínicos, em que as vivências e experiências de nossos pacientes sejam devidamente apreendidas.

\section{Referências bibliográficas:}

Associação Psiquiátrica Americana (APA). (1994). Diagnostic and statistic manual of mental disorder. $4^{\text {th }}$ ed. Washington (DC).

Minkowski, E. (1995). Le Temps Vécu. Paris: Presses Universitaires de France. (Trabalho original publicado em 1933). 